\title{
Evaluation of the Implementation of the e-Citizen in Kenya
}

\author{
Bethseba Ondego \\ School of Computing and Informatics \\ University of Nairobi \\ Nairobi, Kenya
}

\author{
Christopher Moturi \\ School of Computing and Informatics \\ University of Nairobi \\ Nairobi, Kenya
}

\begin{abstract}
Information Communication Technology (ICT) can make a valuable contribution towards the operations of and the services offered to citizens by a government. While the benefits of e-Government initiatives and projects in Kenya cannot be disputed, there are key issues about their successful implementation. A survey about e-Government initiatives in developing countries by [1] show that $50 \%$ have partially failed, 35\% have totally failed and only $15 \%$ have been successful. This research was based on a case study whose aim was to assess the implementation of the Kenya e-Citizen project. Data was collected through interviews and questionnaires from four ministries and the general users/citizens. The questionnaires and interview guides were created based on the six dimensions of the DeLone and McLean Information Systems Success Model. An enhanced model for assessing successful implementation of ICT projects is presented. In addition to the dimensions of the model, stakeholder engagement, has been suggested. The paper concludes by emphasizing the need of stakeholder engagement during the life of any government ICT project. A strategy that would oversee awareness campaigns would be required. Other strategies required would address communication, change management and training.
\end{abstract}

\section{General Terms}

e-Governance, service delivery

\section{Keywords}

Government ICT project; ICT project implementation; ICT project assessment; e-Government initiatives; e-Government service delivery

\section{INTRODUCTION}

The Kenya national long-term development blue-print, Vision 2030 (http://www.vision2030.go.ke/) aims to transform Kenya into a globally competitive and prosperous nation providing a high quality of life to its citizens. The Kenya National ICT Master Plan [2] that is based on Vision 2030 envisages the country as an ICT hub and a globally competitive digital economy. The Master Plan has three pillars namely a) EGovernment services, which aims at ensuring provision of eGovernment information and services as key to improving productivity, efficiency, effectiveness and governance in all key sectors; b) ICT as a Driver of Industry, which aims at transforming key Vision 2030 economic sectors to significantly enhance productivity, global competitiveness and growth; and c) Developing ICT Businesses that can produce and or provide exportable quality products and services that are comparable to the best in the world.
Arising out of the ICT Master Plan, flagship projects that will be implemented over a five-year period have been identified. The main ones are: enabling legal and regulatory framework; persons data hub and associated systems; assets data hub and associated systems; national spatial data infrastructure and associated systems; affordable and quality broadband infrastructure to underserved areas; five Centers of Excellence in ICT education and training; 1-2 year intensive structured training and attachment program producing 500 high-end ICT graduates per year; school network; health network; Science $\&$ Technology park and an ITES center in Konza Technocity connected to other innovation hubs; national electronic single window system; national payment gateway; and national agriculture commodity exchange.

Prior to the above projects, the Government of Kenya has implemented electronic systems in various State Departments and other state-owned institutions, including national tax systems, immigration information system, legal information system, the integrated financial management system and education system. Most of these systems are to be found in the National Treasury, Kenya Revenue Authority, State Departments and Immigration Office. These systems provide partial electronic services to citizens and businesses through Government portals.

These ambitious multi-million dollar ICT-supported initiatives aim to improve government service delivery to her citizenry. A good number of government ICT projects have not been successfully implemented thereby expected benefits not being fully realized from such projects. There has been a high failure rate of these projects despite a lot of funds and resources being channeled into them by governments and other donors such as World Bank. [1] report that $31 \%$ of ICT projects are not delivered within the stipulated budget and another $31 \%$ are not delivered on time. Barriers to the proper implementation of ICT projects in developing countries, can affect the ability to manipulate and use information effectively [3]. This can lead to unsuccessful investments in ICT.

The research sought to assess the implementation of the Kenya government e-Citizen gateway to government services. The study investigated the project from its initiation to implementation, to identify the main factors affect successful implementation of government ICT projects. The e-Citizen (https://www.e-Citizen.go.ke/) is a Kenya Government to Citizen (G2C) portal that provides services including business name search and registration, notice of marriage, registration of marriage, driving licenses, land searches and clearances, passport and visa applications. The system allows citizens to sign up, apply for government services and conveniently pay using mobile money, credit cards, debit cards and online banking. The system also allows foreign residents to apply for 
services. Users receive email and SMS notification every time their application has progressed.

The research investigated the assessment frameworks used in assessing ICT projects in developing countries, established the extent to which e-Citizen Kenya has contributed towards the delivery of various government services to citizens, and proposes a framework that can be used to assess implementation of e-Government projects. The research asked the following research questions: what frameworks have been used to assess ICT projects in developing countries, what causes failure of ICT projects in developing countries, what is the experience of individuals and businesses using services offered by e-Citizen Kenya, how has e-Citizen Kenya contributed to government service delivery, what strategies must be developed to enhance successful implementation of eGovernment initiatives in Kenya, and how can e-Government projects contribute to the socio-economic development of a country.

\section{RELATED WORK}

\subsection{Implementation of ICT Projects}

Numerous ICT projects have been undertaken all over the world most of which have been implemented successfully. However, there are issues in the methods, practices, performance and success in managing ICT projects [4]. In the developing countries, projects that have been designed and implemented, and have the potential to bridge the digital gap, are those that were undertaken in developed countries as opposed to developing countries [5]. [6] empirically explored the complexities of e-government implementation and diffusion challenges in a developing country that is not in an advanced state of e-government development and showed that, irrespective of strong financial support and resources, governments must be prepared to align national ICT strategies with various local level e-government projects, create legislation, implementation guidelines and standards in order to achieve e-government success.

ICT projects are contributing factor to socio-economic growth. [7] show how ICT has positively contributed to the economic development of South Africa. [1] show how ICT acted as an enabler towards the growth of the economy of Malaysia through the Economic Transformation Programme, an initiative meant to increase Malaysia's income by 2020. [8] discuss how ICTs have become deeply involved in the conception and practice of socioeconomic development of developing countries and recommend that viable models be developed and tested thereby ensure sustainability of ICT projects. However challenges are still being experienced in terms of success and sustainability of ICT projects. It is possible to improve efficiency and effectiveness of internal administration within governments through use of ICT [9].

Various authors have identified the gaps between the outcomes in the implementation of various technology initiatives ([9]; [10]; [11]; [12]). These gaps are identified in project, psychological, social, organizational and contextual factors. Those factors applicable in developed nations can be relevant in the developing nation environment but with different weighting of importance [12]. [1] discuss how government ICT projects have not been delivered on time and also the expected benefits not being perceived from these projects. [5] reports that ICT projects are likely to fail due to a number of factors: inappropriate software, inappropriate hardware, inappropriate design and inappropriate implementation approaches. During the design and development of any project, there is need to consider the conditions that the project is to operate in, and this includes the environmental, cultural and economic conditions. There will not be any sustainable development without local support and ownership of the project. [13] have considered the rush to implement ambitious ICT projects at community level with the main focus being the implementation rather the impacts at the recipient level, thus leading to many failures of ICT projects. They have proposed an extended framework to investigate ICT impact on development at village level, with emphasis on the socio-economic aspects of ICT impact, such as mobility restrictions, attitudes towards women and religious influences.

\subsection{ICT Projects in Developing Countries}

ICTs are important to developing countries as they play an important role. [14] express their concern regarding the billions of US dollars that have been channeled towards ICT for Development (ICT4D) projects, yet the effect of such investments is very subtle. Minimal assessment of the impact of ICT4D projects is done. The key issues of ICT in developing countries include sustainability [15], infrastructure [13], adaptation to local social conditions [16] and project management ([15], [4]).

Prioritization of factors that contribute to successful implementation of ICT projects in developed countries differs from that of developing countries ([12]; [17]). The factors that regional ICT initiatives need to fulfill include clarity in specification of sustainability goals, development of innovative business models to capitalize on new ICT opportunities, involvement of community in planning and evaluation of projects [8]. [11] examined the implementation of Digital Village Projects (DVPs) in Kenya and report the constraints that hinder the successful implementation of these projects. These include low level of information literacy, awareness, branding of DVPs, cost of services, and unavailability of affordable bandwidth. The DVP projects, though still young, have contributed significantly to the lives of the beneficiaries. [18] reports on how the Cisco IBSG team (using the Cisco IBSG Digital Villages Development Toolkit) helped the ICT Authority in Kenya identify many challenges of establishing a digital village and how those challenges can be overcome. The [19] guidelines have identified a number of loopholes experienced in ICT projects. The loopholes are as a result of poor monitoring of implementation of ICT projects and lack of proper analysis of the feasibility of projects before they can be undertaken. The guidelines have provided recommendation to enhance integrity in the management of ICT in the public sector.

\subsection{ICT Project Implementation Assessment Models}

Assessment of ICT projects is conducted either as an ex-ante (before implementation) or ex-post (after implementation) procedure. [20] put emphasis on the need to develop frameworks that are suitable in the context of developing countries. Various researchers have proposed different frameworks for the assessment of e-Government projects. [21] present an ex-post three-dimensional framework for the assessment of e-Government initiatives, the dimensions bring e-Government maturity level, stakeholders, and assessment levels. [22] describe the sustainable livelihoods framework as a useful tool in assessing the contribution of ICTs to development projects and argue that applying the sustainable 
livelihood frameworks can help to broaden the project scope and prove more analytically rigorous than other available methods. In a handbook, [23] has reviewed the experiences in supporting ICT pilot projects in developing countries and proposed a framework for assessing the effectiveness of these pilot projects that focuses on monitoring and evaluation (M\&E) components of ICT pilot projects. [13] have highlighted some important perspectives on research into ICT and development by providing an understanding of the intentions behind the adoption and implementation of ICT interventions in developing countries. They have proposed a framework which acknowledges the perspectives of the funding bodies, the organizations responsible for undertaking the intervention, and the to-be-affected communities. [24] draws on the models of enterprise value chains, empowerment and Sen's capability theory to demonstrate ICTs' contribution to conceptions of development as economic growth, as sustainable livelihoods, and as freedom.

[25] report on the amount of investment that has been channeled towards e-Government across the globe. However, not much is known about the impact brought about by the investments - this is partly as a result of lack of assessment guidance. Their paper goes ahead to report the development of a methodology that could be used for assessment in developing countries to justify investments towards eGovernment. In addition, a performance benchmark for future projects will be established. The framework identifies major stakeholders, dimensions for measuring the impact and a methodology of measurement. India is used as an example for testing the framework where assessment results from eight eGovernment projects are presented. Clients preferred computerized service delivery due to fewer journeys, less waiting time and less corruption. However, greater attention needs to be paid to process reform in the design of eGovernment projects. The framework has been successfully adopted by the government of India and used to assess the impact of all mature projects implemented at the national, state and local levels.

The research examined the following models and theories:

a) Diffusion of Innovation Theory [26]: The theory is made up of four main elements: innovation, communication channels, time between decision-making\& adoption of new innovation, social system. Focuses on five groups of people: innovators, early adopters, early majority, late majority and laggards. Diffusion theory can still be a valuable framework for the study of adoption diffusion, provided there is some necessary reorientation concerning the shape of diffusion patterns, segment profiles and adoption determinants [27].

b) DeLone and McLean of Information Systems Success [28]: This model puts emphasis on the importance of measuring success of information systems. The model is made up of seven dimensions of success: information quality, system quality, service quality, use, user satisfaction, individual impact and organizational impact.

c) Hofstede's Cultural Theory [29]: Focuses on culture, attitudes and values of people. Encompasses five dimensions; power distance, uncertainty avoidance, masculinity versus femininity, individualism versus collectivism, long-term perspective versus short-term perspective.

d) Approach Avoidance Theory [30]: The theory shows how behaviors towards positive and negative stimuli are motivated by systems. It emphasizes on understanding various behaviors towards use of technology.

e) Sustainable Livelihood Framework: This model enhances understanding of poverty related issues and how ICTs can help in solving these issues ([31]; [32]). The framework is made up of four elements: livelihood assets, vulnerability context, policies \& processes, and livelihood outcomes.

f) Information Chain Model ([33]; [34], [14]): This model entails obtaining and evaluating data in form of raw facts and figures and processing it to information, which is adapted once it has been deemed to be useful. For data to be counted as information, individuals must be able to access it, assess its relevance and apply it to a specific decision.

\subsection{Conceptual Framework}

The DeLone and McLean Model of Information Systems Success was adopted [28]. The seven dimensions of the model are shown in Fig 1. [9] employed this model and argues that the model can be used to show a causal relationship of how implementation of ICT projects affect IS quality, which in turn affects the perceived benefits.

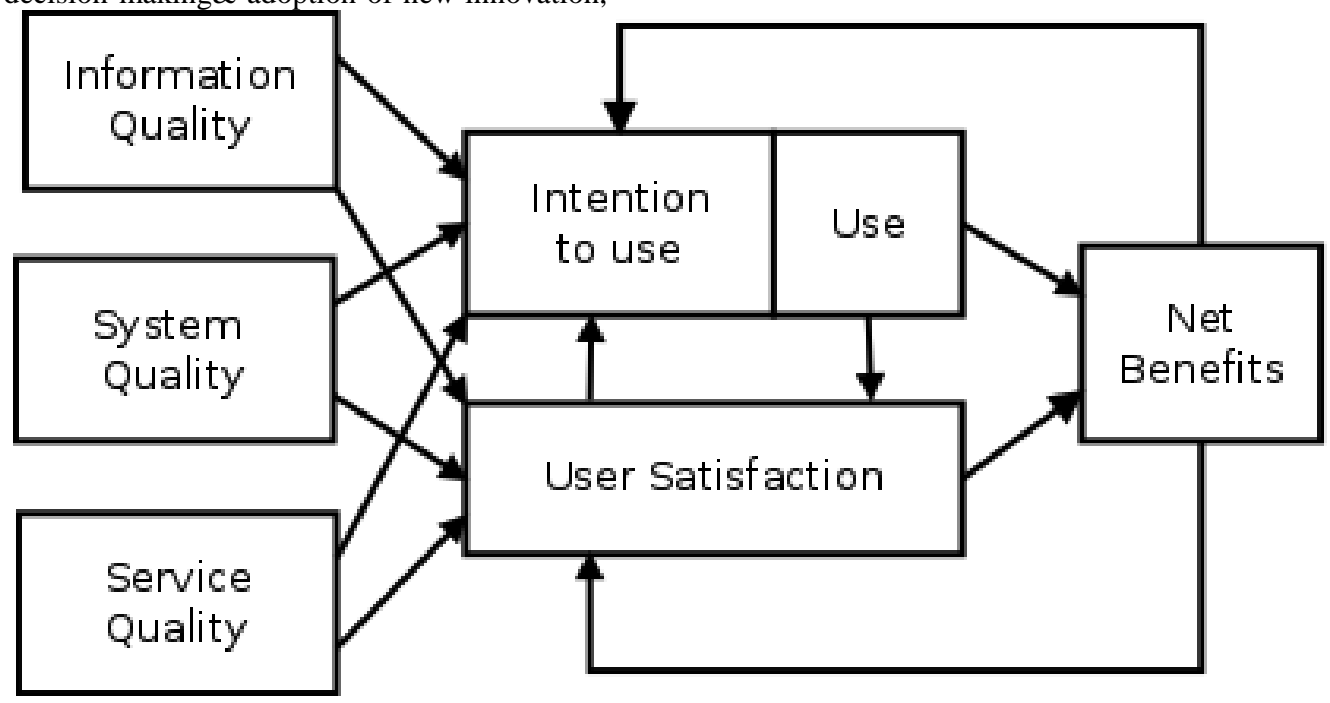

Figure 1: Conceptual Framework (Source: DeLone and McLean, 2003) 


\section{RESEARCH METHODOLOGY}

\subsection{Research Design}

The research adopted a survey approach achieved through questionnaires and observations of respondent's opinions, behaviour, perceptions, attitudes and values regarding the eCitizen project in Kenya. Thematic analysis was developed from qualitative data collected through conducting interviews. This assisted in proofing the suitability of the conceptual framework for the assessment of government projects and testing this model to determine if it can be generalized to other Kenyan government initiatives. The research design enabled the testing of the following hypotheses:

H1: Stakeholder engagement led to successful implementation of e-Citizen project

H2: e-Citizen has had positive impact in delivery of eGovernment services

Hypothesis testing was based on two predictors that were believed to have an effect on successful implementation of eCitizen and one predictor that was believed to have an effect on delivery of e-Government services.

\subsection{Target Population and Sample Size}

A population refers to a complete set of individuals, cases or objects with some common observable characteristics [35]. This study's target population consisted of individuals who make use of the e-Citizen. An accessible population was identified, which was made up of citizens who use the Internet to access government information and services; general users/citizens, the e-Citizen Portal secretariat, Huduma Centre manager, project managers and their teams from the four key ministries: Ministry of Land, Housing \& Urban Development, Department of Immigration Services, National Transport \& Safety Authority, and Office of the Attorney General \& Department of Justice.

A sample of 150 was drawn through random and purposive sampling. The former was used to select the general users of the e-Citizen portal, while the latter was used to select individuals that had the required information with respect to the objectives of this study. For random sampling, various organizations/SMEs were identified, each given a number out of which six were selected randomly. This allowed each unit a chance to be included in the sample. A statistical formula suggested by [35] was used to determine the sample size. The formula is argued to be suitable in cases where the sample is not known.

\subsection{Data Collection}

Data was collected through interviews, direct observation and administration of questionnaires. Interview guides and questionnaires were constructed based on the objectives of the study. Individuals who spearheaded projects in the various ministries were interviewed using an interview guide. Most of the data was collected through questionnaires as they provide an opportunity for anonymity hence high response rate. Permission to carry out the research was obtained in advance from various organizations and ministries that took part in the study. Quantitative data was collected through questionnaires that were administered to two groups of respondents i.e. the ministry users and the general users (other citizens who are not part of the various ministries), while qualitative data was collected through interviewing the various project managers (in this case heads of ICT) from the various ministries that took part in the study.

\subsection{Data Analysis}

The data that was collected was grouped into various categories after which it was entered in Microsoft Excel then coded. Quantitative data was analyzed using descriptive statistics; tables, percentages and frequency counts to describe distributions. Since the data was not large, Microsoft Excel was found adequate. For the qualitative data, various themes were established from the coded data, which were then winnowed to a manageable few.

\subsection{Validity and Reliability}

An interview guide and questionnaire were developed; both were scrutinized by an experienced researcher and two $\mathrm{PhD}$ students before they were administered. The test-retest method of assessing reliability was employed where the same instrument was administered twice to the same group of subjects at two separate times. All the 15 questionnaires that were administered the very first time were returned. Two questionnaires were not returned the second time and this is because the respondents were on leave. However, all the questionnaires that were administered the second time had the same response as those administered the first time. This proved that the questionnaires were reliable hence fit for use in the study. Final refinement of the questionnaire was done and contact persons from the various organizations and / or sectors that were participating in the study identified.

\section{RESULTS AND DISCUSSION}

\subsection{Response Rate}

Out of the 150 respondents sampled, there were 106 valid responses giving a response rate of $71 \%$, which was considered satisfactory.

Table 1: Respondents Distribution (Source: Research Data, 2015)

\begin{tabular}{|l|c|c|c|}
\hline \multicolumn{1}{|c|}{ Organisation } & Target & Response & Percentage \\
\hline $\begin{array}{l}\text { Ministry of Land, } \\
\text { Housing \& Urban Dev }\end{array}$ & 12 & 8 & 7.5 \\
\hline $\begin{array}{l}\text { Attorney General \& } \\
\text { Dept of Justice }\end{array}$ & 10 & 1 & 0.9 \\
\hline $\begin{array}{l}\text { Department of } \\
\text { Immigration Services }\end{array}$ & 15 & 9 & 8.5 \\
\hline $\begin{array}{l}\text { National Transport \& } \\
\text { Safety Authority }\end{array}$ & 7 & 2 & 1.9 \\
\hline e-Citizen Secretariat & 2 & 1 & 0.9 \\
\hline Huduma Centre Staff & 14 & 13 & 12.3 \\
\hline e-Citizen Users & 90 & 72 & 67.9 \\
\hline Total & $\mathbf{1 5 0}$ & $\mathbf{1 0 6}$ & $\mathbf{1 0 0}$ \\
\hline
\end{tabular}

An additional 34 citizens at one of the Huduma Centres were engaged and observed. This particular category consists of individuals who are oblivious of the e-Citizen portal. Huduma Centre (http://www.hudumakenya.go.ke/) is a one-stop shop for government services where all services are offered under one roof. 


\subsection{Demographics}

Male respondents accounted for $68 \%$ while female accounted for $32 \%$. The former were more willing to participate as a good number of them had used the portal before. Most of the respondents were between the ages of 31 to 35 years, followed by 26 to 30 years and then 18 to 25 years. $89 \%$ of the respondents were employed most of whom worked in offices where they could easily acquire resources i.e. in terms of computers and internet for easy access of government information and services. Respondents with Bachelors degree formed the largest proportion (49\%), followed by those who had a Masters/PhD who accounted for $30 \%$ of the sample size and finally those who had a Diploma/higher diploma who accounted for $18 \%$. The study population had a fairly high level of education, which could impact positively on understanding and adopting of technology (e-Citizen). $46 \%$ of the respondents had an advanced level of IT experience, followed by $29 \%$ who had intermediate level of IT experience. The rest (25\%) accounted for those that were IT experts.

\subsection{Hypothesis Testing}

The study had two hypotheses $\mathrm{H} 1$ and $\mathrm{H} 2$ that were tested by conducting linear regression on the independent and dependent variables.

H1: Stakeholder engagement led to successful implementation of e-Citizen project

The predictors (independent variables) for $\mathrm{H} 1$ were:

i) $\mathrm{x} 1$ - the Kenyan government engaged the public/citizens during development of the e-Citizen project.

ii) $\mathrm{x} 2$ - the Kenyan government communicates promptly to the public, providing updates and progress of the project.

The dependent variable was: y - I plan to continue using eCitizen in future.

Table 2: H1 analysis output (Source: Research Data, 2015)

\begin{tabular}{lr}
\hline \multicolumn{2}{c}{ Regression Statistics } \\
\hline Multiple R & 0.179786191 \\
R Square & 0.032323075 \\
Adjusted R Square & 0.007824925 \\
Standard Error & 0.808598617 \\
Observations & 82 \\
\hline
\end{tabular}

\begin{tabular}{|c|c|c|c|c|c|c|}
\hline \multicolumn{7}{|l|}{ ANOVA } \\
\hline & $d f$ & SS & MS & $F$ & Significance $F$ & \\
\hline Regression & 2 & 1.725342651 & 0.862671326 & 1.319408794 & 0.273117934 & \\
\hline Residual & 79 & 51.65270613 & 0.653831723 & & & \\
\hline \multirow[t]{2}{*}{ Total } & 81 & 53.37804878 & & & & \\
\hline & Coefficients & Standard Error & $t$ Stot & P-value & Lower 95\% & Upper 95\% \\
\hline Intercept & 4.55888782 & 0.283544396 & 16.07821519 & $1.25035 E-26$ & 3.994506826 & 5.123268814 \\
\hline $\mathrm{x} 1$ & 0.03412899 & 0.096854861 & 0.352372573 & 0.725497195 & -0.158655779 & 0.226913772 \\
\hline$x 2$ & -0.13284369 & 0.082319736 & -1.613752685 & 0.110568684 & -0.296697027 & 0.031009638 \\
\hline
\end{tabular}

Table 2 has coefficients of $\mathrm{x} 1$ and $\mathrm{x} 2$ as 0.034128997 and 0.132843694 respectively. This means that there is an increase (in future usage of e-Citizen portal) of 0.034128997 for every 1 unit increase in stakeholder engagement/communication. However, this increase is not statistically significant $(p>0.05)$ hence could be attributed to random chance. Since two independent variables were used, their coefficients test the unique effect of each independent variable while the F-test (Significance F) test the joint effects of both variables together. This can therefore be interpreted to imply that there is a weak positive relationship between stakeholder engagement/communication and future usage of the e-Citizen portal. On the other hand, there is a decrease (in future usage of e-Citizen portal) of 0.132843694 for every 1 unit increase in stakeholder engagement/communication. This decrease is not statistically significant as $\mathrm{p}>0.05$. This can therefore be interpreted to imply that there is a weak negative relationship between stakeholder engagement/communication and future usage of the e-Citizen portal. Also called Pearson correlation coefficient, this is a measure of the strength of association between future usage of the e-Citizen portal and engagement of and communication to the public/citizens during the life of the project. A multiple $\mathrm{R}$ of 0.179786191 indicates a weak positive relationship between stakeholder engagement/communication and future usage of the portal. An R Square of 0.032323075 indicates that only $3.2 \%$ of the changes in the future usage of the portal can be explained by stakeholder engagement/communication. The remaining $96.8 \%$ can be explained by other factors. Despite a number of respondents having claimed that the Kenyan government did not engage the public in the development of the e-Citizen project, this does not necessarily mean that the project failed. On the contrary, the e-Citizen portal was implemented successfully and this is due to the fact that the government employed a strategy whereby other options of accessing some of the government services were eliminated thereby forcing the citizens to access these services via the e-Citizen portal.

$\mathrm{H} 2$ : e-Citizen has had positive impact in delivery of eGovernment services

The predictor (independent variable) for $\mathrm{H} 1$ was: $\mathrm{x} 1$ - mode of access of government information and services. While the dependent variable was: $y$ - the ability of e-Citizen to enable citizens accomplish tasks more quickly and with much ease. 
Table 3: H2 analysis output (Source: Research Data, 2015)

SUMMARY OUTPUT

\begin{tabular}{lr}
\hline \multicolumn{2}{c}{ Regression Statistics } \\
\hline Multiple R & 0.661799522 \\
R Square & 0.437978607 \\
Adjusted R Square & 0.430953339 \\
Standard Error & 0.237250529 \\
Observations & 82 \\
\hline
\end{tabular}

\begin{tabular}{|c|c|c|c|c|c|}
\hline & $d f$ & ss & MS & $F$ & Significance $F$ \\
\hline Regression & 1 & 3.509170057 & 3.509170057 & 62.34333599 & $1.29381 \mathrm{E}-11$ \\
\hline Residual & 80 & 4.503025065 & 0.056287813 & & \\
\hline Total & 81 & 8.012195122 & & & \\
\hline
\end{tabular}

\begin{tabular}{|c|c|c|c|c|c|c|}
\hline \multicolumn{7}{|c|}{ Standard } \\
\hline & Coefficients & Error & t Stat & P-value & Lower 95\% & Upper 95\% \\
\hline Intercept & 2.192307692 & 0.13958597 & 15.70578827 & $3.69375 \mathrm{E}-26$ & 1.914522764 & 2.470092621 \\
\hline $\mathrm{x} 1$ & -0.249351772 & 0.031580386 & -7.895779631 & $1.29381 \mathrm{E}-11$ & -0.312198743 & -0.186504801 \\
\hline
\end{tabular}

Table 3 has coefficients of $x 1$ as -0.249351772 . This means there is a decrease (in the dependent variable) of 0.249351772 for every 1 unit increase in the independent variable. This decrease is however not statistically significant as $\mathrm{p}>0.05$. Since one independent variable was used, the p-value for its coefficient is exactly the same as the p-value for the ANOVA F-statistic (Significance F) as they test the same thing. A multiple $\mathrm{R}$ of 0.661799522 indicates a fairly strong positive relationship between the mode of access of government services and the ability of citizens to accomplish tasks more quickly and with much ease via the e-Citizen portal. An R Square of 0.437978607 indicates that $43.8 \%$ of the changes in the dependent variable can be explained by the independent variable. The remaining $56.2 \%$ can be explained by other factors. This can therefore be interpreted to imply that there is a weak relationship between the mode of access of government services and the ability of citizens to accomplish tasks more quickly and with much ease. This could be due to the fact that only a few of the government services have been made available on the e-Citizen portal hence a good number of these services are yet to be availed online. This then causes the impact of e-Citizen not to be realized/felt much as yet.

\subsection{Dimensions of the DeLone and McLean Model}

The results which test the dimensions of the DeLone and McLean Model have been summarized in table 4.

Table 4: DeLone and McLean Dimensions (Source: Research Data, 2015)

\begin{tabular}{|l|c|c|c|c|c|c|}
\hline \multicolumn{1}{|c|}{ Statements } & Agree & \% & Neutral & \% & Disagree & \% \\
\hline Access government information (24/7) & 68 & 64 & 20 & 19 & 10 & 9 \\
\hline Users have been trained on how to use e-Citizen portal & 8 & 8 & 28 & 26 & 46 & 43 \\
\hline Ease of learning how to operate e-Citizen & 72 & 68 & 6 & 6 & 4 & 4 \\
\hline Ease of using e-Citizen if trained & 51 & 48 & 25 & 24 & 6 & 6 \\
\hline e-Citizen /government services affordable & 62 & 58 & 14 & 13 & 6 & 6 \\
\hline Accomplish tasks quickly/with much ease & 83 & 78 & 15 & 14 & 3 & 3 \\
\hline Services packaged well for easier access & 73 & 69 & 19 & 18 & 7 & 7 \\
\hline Queries answered in good time & 60 & 57 & 11 & 10 & 12 & 11 \\
\hline Relevant, adequate \& accurate information on services & 68 & 64 & 32 & 30 & 3 & 3 \\
\hline e-Citizen useful to citizens & 87 & 82 & 23 & 22 & 3 & 3 \\
\hline e-Citizen not useful/inefficient availability of info \& services & 12 & 11 & 29 & 27 & 58 & 54 \\
\hline Experience hardware/software problems & 21 & 19 & 29 & 27 & 43 & 40 \\
\hline Difficulties in usage due to lack of info \& awareness campaigns & 19 & 18 & 19 & 18 & 44 & 42 \\
\hline Awareness campaigns not satisfactory & 47 & 44 & 16 & 15 & 19 & 18 \\
\hline
\end{tabular}




\begin{tabular}{|l|c|c|c|c|c|c|}
\hline Kenyan government communicates promptly to public & 22 & 21 & 37 & 35 & 44 & 42 \\
\hline Kenyan government engaged public during development & 16 & 15 & 41 & 39 & 46 & 43 \\
\hline Satisfactory security \& privacy measures & 36 & 34 & 36 & 34 & 10 & 9 \\
\hline Continual future usage & 84 & 79 & 12 & 11 & 3 & 3 \\
\hline
\end{tabular}

\subsubsection{System Quality}

Section System quality focused on the systems' usability aspects and performance characteristics where the following elements were considered important: ease of usage/learning, integration, flexibility/reliability, functionality, response time, interactivity and adoption. Respondents were asked questions touching on: accessibility of government information 24/7, mode of payment for government services, user training on use of e-Citizen portal, ease of learning on usage of e-Citizen portal, ease of accomplishment of tasks performed on eCitizen, hardware/software issues, security and privacy measures. Based on the findings, it was concluded that the quality of the system was good.

\subsubsection{Information Quality}

The selected information quality elements were: accuracy, completeness, relevance, availability and security. Factors that attribute to information quality are: $24 / 7$ access of government information and services, provision of relevant and accurate information regarding services offered via the portal, provision of efficient information and services, ease of use of the portal, awareness campaigns, communication by the government and security measures. This study concluded that users trust and have confidence in the information provided on the portal.

\subsubsection{Service Quality}

This dimension measures how well the service level is delivered and if it matches the expectations of the users. It focuses on the quality of support accorded to the user of a system. Respondents (general users) were asked if their queries were answered in good time: $57 \%$ agreed, $11 \%$ disagreed, while $10 \%$ were neutral. This can be interpreted to imply that the support given to the users is of high quality hence this would determine if or not the users would continue to use the system.

\subsubsection{Intention to Use, User Satisfaction and Net Benefits}

These three dimensions are closely related. Intention to use feeds into the impact and benefits of an IS system and it is determined by the three dimensions discussed above. User satisfaction is determined by the experience a user has while using a system. Good user experience would result in greater user satisfaction and vice versa. What the study measured is the entire user experience during their interaction with the eCitizen portal. Net benefits is made up of two elements i.e. individual impact and organizational impact. e-Citizen being a one stop shop that offers most of the government services, has helped citizens in saving time as they are able to acquire various services at the same time and they don't need to queue anywhere in order to acquire these services. There has been an increase in revenue collected by the government and this has been attributed to the elimination of queues hence being able to serve as many citizens, the possibility of making payments online and the fact that digitization has made it easier for the government to follow clear procedures in the collection of money (majorly through Mpesa) and accounting for it.

\subsection{Qualitative Analysis}

Qualitative data analysis seeks to make general statements on how categories or themes of data are related [35]. Qualitative data was collected from the four ministries by interviewing the various individuals in ICT departments of these ministries. Three major themes emerged from the qualitative data that was collected; synergy, awareness \& training, resistance \& change management. Research revealed that there is lack of synergy within the government, this is likely to result in duplication of services thereby wastage of scarce government resources. More public awareness needs to be done as a good number of citizens are oblivious of what e-Citizen is and what it does. Awareness is even more critical in view of challenges identified by other researchers ([3]; [11], [18]). Despite the introduction of e-Citizen, resistance still being experienced and therefore this is an issue that needs to be addressed by coming up with a good change management strategy that would oversee this.

\subsection{Enhanced Model for Assessing Implementation of ICT Projects}

The DeLone and McLean model has 6 dimensions: information quality, system quality, service quality, intention to use/use, user satisfaction and net benefits. This paper proposes that one dimension be incorporated into the model: stakeholder engagement, which would be determined by communication, training and awareness that needs to be done by the government. Even though hypothesis indicate a weak relationship between stakeholder engagement and successful implementation of e-Citizen project, results show that only $15 \%$ of respondents agreed that the Kenyan government engaged the public during development of e-Citizen, the rest either disagreed or did not know. This proposal is consistent with ([21]; [23]; [36]; [37]; [38]). 


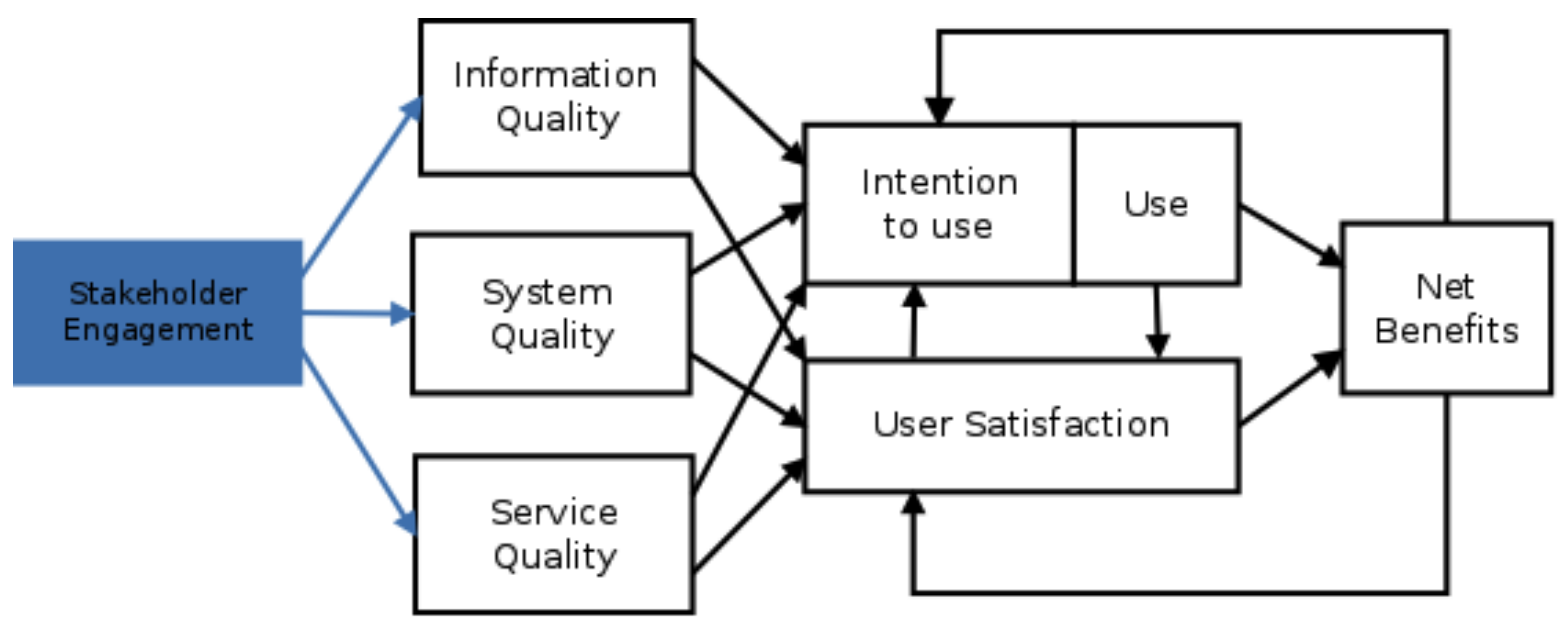

Figure 2: Enhanced Model (Source: Research Survey Data, 2015)

\section{CONCLUSION AND RECOMMENDATIONS}

This research sought to establish the extent to which e-Citizen Kenya has contributed towards the delivery of various government services to citizens. To achieve this objective, the research investigated six frameworks used in assessing ICT projects in developing countries and adopted the DeLone and McLean of Information Systems Success model in developing a conceptual framework. Questionnaires derived from the conceptual framework were administered to individuals and businesses, with focus on user experience in interacting with the e-Citizen portal. Interviews were conducted with project managers of the key ministries and departments that were involved in the implementation of e-Citizen implementation. The answers informed the extent to which e-Citizen Kenya has contributed to government service delivery.

The analysis of the quantitative data generated from the completed questionnaires and the identification of various issues that arose from the qualitative data that was collected through conducting interviews, has informed the proposed model which has more constructs incorporated. The analysis covered six dimensions namely; information quality, system quality, service quality, intention to use/use, user satisfaction and net benefits. This research proposes one additional dimension to be incorporated into the DeLone and McLean model: stakeholder engagement. This will improve the assessment process of implementation of ICT projects in developing countries and address issues identified by other researchers ([1]; [10]; [11])

The research has contributed to strategies that would enhance successful implementation of e-Government initiatives and hence contribute to the socio-economic development of developing countries ([6]; [7]; [25]). The findings are not only relevant to other researchers but practitioners such as system implementers, project managers and government policy makers.

The research was limited to the e-Citizen project in an urban region (Nairobi). There is need for inclusion of rural areas where e-Government services are even more needed. The research should be extended to other similar projects such as Huduma Centres in order to learn from past experience and avoid making the same mistakes.

\section{REFERENCES}

[1] Nawi, H. S. A., Rahman, A. A., Ibrahim, O. (2012). Government ICT Project Failure Factors: Project Stakeholders' Views. Journal of Information Systems Research and Innovation, 2, 69-77.

[2] ICTMP (2014). The Kenya National ICT Master Plan $2013 / 14-2017 / 18$

[3] Tilvawala, K., Myers, M. D., \& Andrade, A. D. (2009). Information literacy in Kenya. The Electronic Journal of Information Systems in Developing Countries, 39.

[4] Othman, M., Zain, A. M., \& Hamdan, A. R. (2010). A Review on Project Management and Issues Surrounding Dynamic Development Environment of ICT project: Formation of Research Area. JDCTA, 4(1), 96-105.

[5] Reijswoud, V. (2009). Appropriate ICT as a Tool to Increase Effectiveness in ICT4D: Theoretical Considerations and Illustrating Cases. Journal on Information Systems in Developing Countries, (p. 1-18).

[6] Weerakkody, V., El-Haddadeh, R., \& Al-Shafi, S. (2011). Exploring the complexities of e-government implementation and diffusion in a developing country: Some lessons from the State of Qatar. Journal of Enterprise Information Management, 24(2), 172-196.

[7] Langmia, K. (2005). The role of ICT in the economic development of Africa: The case of South Africa. Journal of Education and Development using Information and Communication Technology, 2(4), 144-156.

[8] Kasigwa, J., Williams, D., Baryamureeba, V. (2006). The Role of ICTs and their Sustainability in Developing Countries. (p. 78-88).

[9] Gichoya, D. (2005). Factors Affecting the Successful Implementation of ICT Projects in Government. Journal of e-Government, 3(4), 175-184.

[10] Brooks, L., \& Eke, B. (2010). IS Project Escalation in Developing Countries. In Proceedings of the Americas Conference on Information Systems, AMCIS (p. 430).

[11] Atieno, L.V. \& Moturi , C.A. (2014). Implementation of Digital Village Projects in Developing Countries - Case of Kenya. British Journal of Applied Science \& Technology, 4(5), pp 93-807. 
[12] Atsu, M. Y., Andoh-Baidoo, F. K., Osatuyi, B., \&Amoako-Gyampah, K. (2010). An exploratory study of the contextual factors that influence success of ICT projects in developing nations: A case study of a telecommunications company in Ghana. Journal of Information Technology Case and Application Research, 12(3), 56-81.

[13] Ashraf, M., Swatman, P. Hanisch, J. (2008). An Extended Framework to Investigate ICT Impact on Development at the Micro (Community) Level.

[14] Heeks, R., Molla, A. (2009). Impact Assessment of ICTfor-Development Projects: A Compendium of Approaches.(p. 1-160).

[15] Pade-Khene, C., Mallinson, B., \& Sewry, D. (2011). Sustainable rural ICT project management practice for developing countries: investigating the Dwesa and RUMEP projects. Information Technology for Development, 17(3), 187-212.

[16] Avgerou, C. (2008). Information systems in developing countries: a critical research review. Journal of information Technology, 23(3), 133-146.

[17] Ssewanyana, J., \& Busler, M. (2007). Adoption and usage of ICT in developing countries: Case of Ugandan firms. International Journal of Education and Development using ICT, 3(3).

[18] Drury, P. (2011). Kenya's Pasha Centres: Development Ground for Digital Villages. Cisco, The Netherlands. pp $1-13$.

[19] KACC (2008). The Kenya Anti Corruption Commission - Corruption Prevention Guidelines on ICT Systems in the Public Sector.

[20] Otieno, I., \& Omwenga, E. (2014). Towards the Development of a Citizen-Centric Framework for Evaluating the Impact of eGovernment: A Case Study of Developing Countries, (p. 1-9).

[21] Esteves, J., \& Joseph, R. C. (2008). A comprehensive framework for the assessment of eGovernment projects. Government information quarterly, 25(1), 118-132.

[22] Parkinson, S., \& Ramirez, R. (2007). Using a sustainable livelihoods approach to assessing the impact of ICTs in development. The Journal of Community Informatics, 2(3).

[23] Batchelor, S. J. (2007). Framework for the assessment of ICT pilot projects Beyond Monitoring and Evaluation to Applied Research. Available from http://www.infodev.org/infodev-

files/resource/InfodevDocuments_4.pdf
[24] Heeks, R. (2010). Do information and communication technologies (ICTs) contribute to development?. Journal of International Development, 22(5), 625-640.

[25] Bhatnagar, S. C., \& Singh, N. (2010). Assessing the Impact of E-government: A Study of Projects in India. Information Technologies \& International Development, 6(2), pp-109.

[26] Peansupap, V., Walker, D. (2006). Innovation diffusion at the implementation stage of a construction project: a case study of information communication technology, ( $\mathrm{p}$. 321-332).

[27] De Marez, L., Evens, T., \& Stragier, J. (2011). Diffusion theory vs. today's ICT environment. Observatorio (OBS*), 5(3).

[28] DeLone, W., McLean, E. (2003).TheDeLone and McLean Model of Information Systems Success: A TenYear Update, 19(4), 9-30.

[29] Kirkman, B., Lowe, K., Gibson, C. (2006). A Quarter Century of Culture's Consequences: A Review of Empirical Research Incorporating Hofstede's Cultural Values Framework. Journal of International Business Studies, (p. 285-320).

[30] Elliot, A. (2006). The Hierarchical Model of ApproachAvoidance Motivation. (p. 1-6).

[31] Duncombe, R. (2006). Using the Livelihoods Framework to Analyze ICT Applications for Poverty Reduction through Microenterprise, 3(3), 81-100.

[32] Ashley, C., \& Carney, D. (1999). Sustainable livelihoods: Lessons from early experience (Vol. 7, No. 1). London: Department for International Development.

[33] Heeks, R. (1999). Information and Communication Technologies, Poverty and Development. (p. 1-19).

[34] Heeks, R. (2005). Foundations of ICTs in Development: The Information Chain eDevelopment Briefing 3. Manchester: Development Informatics Group, University of Manchester

[35] Mugenda, M., Mugenda, G. (1999). Research Methods. Quantitative and Qualitative Approaches. Nairobi, Kenya.

[36] Legris, P., Collerette, P. (2006). A Roadmap for IT Project Implementation: Integrating Stakeholders ad Change Management. (p. 1-12).

[37] Hassan, H. S., Shehab, E., \&Peppard, J. (2011). Recent advances in e-service in the public sector: State-of-the-art and future trends. Business Process Management Journal, 17(3), 526-545.

[38] Price, A., Chahal, K. (2006). A Strategic Framework for Change Management. (p. 237-251). 